\title{
A Feasibility Study Assessing a Culturally Relevant Physical Activity Intervention for Midlife Filipino Women
}

\author{
Aisha Bhimla ${ }^{1,2, *}$, Selen Razon ${ }^{3}$, Grace X. $\mathbf{M a}^{2}$, Gabrielle Salvatore ${ }^{1}$, Julia Trout ${ }^{1}$, Michael Sachs ${ }^{1}$ \\ ${ }^{1}$ Department of Kinesiology, Temple University, Philadelphia, USA \\ ${ }^{2}$ Center for Asian Health, Lewis Katz School of Medicine, Temple University, Philadelphia PA, USA \\ ${ }^{3}$ Department of Kinesiology, West Chester University, West Chester, PA 19383 \\ *Corresponding author: aisha.bhimla@temple.edu
}

Received August 10, 2018; Revised September 11, 2018; Accepted October 09, 2018

\begin{abstract}
Introduction: Regular participation in physical activity (PA) can prevent chronic disease and mental illness across the lifespan and during later adulthood. Few PA interventions have been implemented in underserved Filipino American women to address health related outcomes among this population. Purpose: This study assessed the effect of a culturally relevant community-based Zumba ${ }^{\circledR}$ program on anthropometrics, physical fitness, and exercise motivation among midlife Filipino women. Methods: We employed a single-group pretest-posttest design. Twenty-one female participants were recruited from Filipino community-based organizations (CBOs) in the Greater Philadelphia region. Sixteen female participants $(\mathrm{N}=16, \mathrm{M}$ age $=55.88, \mathrm{SD}= \pm 9.479)$ completed the 8-week program, which consisted of attending three Zumba classes per week at the Filipino CBOs, which was led by a certified Zumba instructor of Filipino ethnicity. A paired samples t-test was conducted to detect the differences between the pre-and post-outcome measures. Results: A total of 16 out of 21 participants completed the intervention and the post-intervention assessment (76\% retention rate). Adherence to the Zumba classes was $42.46 \%$ among participants who completed the post-intervention. With regards to pre- and post- primary outcome measures, there was a significant reduction in body weight $(-3.18 \pm 2.61 \mathrm{lbs}$., $\mathrm{p}<0.001)$, body mass index (BMI) $\left(-0.44 \pm 0.49 \mathrm{~kg} / \mathrm{m}^{2}\right.$, $\mathrm{p}=0.002)$, and increase in flexibility $(1.93 \pm 3.22 \mathrm{~cm}, \mathrm{p}=0.035)$ among participants. There were no statistically significant differences in exercise motivation inventory (EMI-2) subscales, except affiliation scores increased among participants overall $(-0.750 \pm 1.38, \mathrm{p}=0.047)$. Discussion: The incorporation of this community-based program can be a promising approach for potentially enhancing health outcomes for underserved Asian American populations such as Filipino Americans. Future research can examine the long-term impacts of Zumba and other exercise modalities for chronic disease prevention and management.
\end{abstract}

Keywords: Asian American, physical activity, community intervention, Filipino

Cite This Article: Aisha Bhimla, Selen Razon, Grace X. Ma, Gabrielle Salvatore, Julia Trout, and Michael Sachs, "A Feasibility Study Assessing a Culturally Relevant Physical Activity Intervention for Midlife Filipino Women.” Journal of Physical Activity Research, vol. 3, no. 2 (2018): 89-95. doi: 10.12691/jpar-3-2-5.

\section{Introduction}

Physical activity (PA) is a lifestyle behavior that has demonstrated protective effects towards the development of cardiovascular risk factors such as hypertension, overweight/obesity, hyperlipidemia and type 2 diabetes [1-6]. Despite the well-known benefits of PA, there are significant disparities in participation rates among specific racial/ethnic minority populations [7]. Asian Americans have reported lower rates of PA in comparison to Non-Hispanic Whites and other ethnic groups $[8,9,10,11,12]$. Due to national-level data identifying Asians Americans as a homogenous group, this has conveyed false measures regarding their health and specifically the hidden disparities in physical activity and chronic disease rates
$[13,14,15,16]$. Filipinos represent the second largest Asian immigrant population in the US, yet the behaviors affecting PA among this population are largely understudied [17]. Studies that assessed general PA levels among Filipinos in the northeast US found rates of participation to be lower than the national average $[8,18]$. In a recent study among Asian American subgroups in California, middle-aged (45-64 years) Filipinos had the lowest odds of meeting the American College of Sport Medicine's (ACSM) PA recommendations compared to other ethnic groups, including Chinese, South Asian, Japanese, Korean and Vietnamese [15].

Considering that PA participation can assist in preventing chronic disease, which is persistent among Filipino Americans, efforts to increase PA within Filipino Americans need further inquiry [8, 9, 19, 20]. Filipinos face the highest rates of overweight and obesity among all 
Asian American subgroups [10,21]. Evidence suggests that $30.6 \%$ of females and $46.1 \%$ of males were overweight, and $6 \%$ and $15.8 \%$ of females and males were obese, respectively, within the Filipino community in New Jersey [22]. Recent data have also indicated that 53\% and $67.5 \%$ have been diagnosed with hypertension within the Filipino communities of greater New York City and Philadelphia regions [18,23]. Furthermore, Filipino Americans are at a higher risk for coronary heart disease compared to other Asian American groups [24,25,26]. With regards to diabetes, a study conducted in California found that the age adjusted odds of type 2 diabetes was four times greater in Filipinos than Caucasians [27].

Despite the high rates of chronic disease, there is a paucity of research on Filipino Americans and their PA behaviors. Among the limited studies that have examined facilitators and barriers to PA among this population, participants reported that the presence of chronic health conditions as both a motivator and barrier to PA among older Filipinos [9]. Nevertheless, a general lack of motivation has been consistently identified as a primary barrier to PA [9,19]. Additional barriers included personal factors such as overall health concerns, lack of personal safety, environmental conditions and lack of culturally relevant exercise modalities and facilities that hinder participation in PA $[19,28]$. Potential motivators and barriers to PA among Filipino Americans require further investigation to increase PA levels among this ethnic group. Consequently as a result of low PA, there is a need to design and test the effectiveness of alternative modalities to increase PA and health outcomes within Filipinos [10,28].

Interventions that incorporate culturally relevant and tailored strategies to increase PA and healthy lifestyle behaviors have shown promising outcomes for promoting health among ethnic minorities [29-33]. The impact of a culturally appropriate PA intervention on health and physical outcomes has not been previously studied in Filipino Americans. This study aims to address an important knowledge gap surrounding how culturally relevant PA interventions affect the health and well-being of Asian Americans.

This study will investigate the effects of a culturally relevant PA intervention among midlife Filipino women living in the Philadelphia Metropolitan Area. More specifically, we will assess the acceptability, feasibility and potential effects of a community-based Zumba ${ }^{\circledR}$ program on health and physical outcomes including body mass index (BMI), weight, flexibility, blood pressure, waist circumference, aerobic fitness and exercise motivation among midlife Filipino women. As this study was an exploratory study, no priori hypothesis was formulated.

\section{Methods}

\subsection{Study Procedures}

This study was approved by the Institutional Review Board at Temple University. We obtained written informed consent from participants prior to participation in the study. The study design was a single group pre-test posttest design. The recruitment and development of the study intervention involved community based participatory research (CBPR) approach to addressing and improving the health of a community [34,35,36]. Researchers collaborated with community-based organizations (CBOs) on this project, and CBO leaders were actively involved in all aspects of the study from study design to implementation. The selected intervention was designed using previous work involving community leaders from CBOs and female community members. Participants were invited to take part in a survey and focus group, which aimed to determine what specific cultural components and factors would be incorporated into the current PA intervention. Based on response of the participants, we designed a culturally relevant intervention for our specific population. After careful consideration, multiple meetings with CBO leaders and discussion of what intervention to choose, Zumba was chosen as the intervention, which was highly regarded by Filipino women and could potentially help the community increase PA levels [37]. Additionally, the surrounding community also held Zumba classes frequently, making it easily accessible, however it was not regularly attended by participants previously.

\subsection{Participants and Recruitment}

Participants were recruited to participate in the study from July 2016-September 2017. Eligibility criteria included: (1) being female, (2) currently living in the Philadelphia Metropolitan Area, (3) not currently meeting the PA guidelines of the Centers for Disease Control and Prevention (CDC), i.e., 150 minutes of moderate activity per week [1], and (4) being over 40 years of age. Participants were recruited through Filipino CBOs located in the Philadelphia metropolitan area. CBO leaders posted flyers around their surrounding neighborhoods, relevant stores/restaurants, through email and word of mouth. Advertisements and flyers were posted in the community centers and restaurants, as well as sent out through email and word of mouth. We used convenience sampling to screen and recruit participants for our study.

\subsection{Intervention}

The 8-week Zumba ${ }^{\circledR}$ intervention was selected as the culturally appropriate aerobic exercise program for our study participants. Zumba classes met three times per week for 8 consecutive weeks. The classes were taught by a bilingual Filipino certified Zumba instructor with over 10 years of experience teaching Zumba to adults. As Filipinos are viewed as highly acculturated to American culture and values, the music chosen for the Zumba workouts included Western and Latin music typically played with this activity [38]. Each class lasted between 60 and 75 minutes and included a warm-up and cool-down. All classes were held at a Filipino community center and local church, located within a 5-mile radius of where participants resided.

The Zumba class consisted of a dance routine, which included basic Latin dance routines and Zumba toning moves. Every class focused on balance, abdominal engagement, and cardio. Of these, Zumba Toning incorporated the challenge of adding resistance using Zumba Toning sticks or light dumbbells that ranged 
between 1 and 2.5 pounds. The instructor incorporated the weights for the last half of the class, allowing the participants to focus on specific muscle groups. The toning sticks enhanced each participant's sense of rhythm and coordination, while also toning target zones such as arms, abdomen, and lower body. The instructor used moves such as arm lifts and kicks found in the merengue, cardio directional moves used in salsa dancing, merengue arm lift and kick, salsa's cardio directional moves, abdominal moves from hip hop, bachata hip sways for core engagement, cha-cha footwork for grace and coordination, and cumbia balance steps. A moderate to low intensity song at the end of each workout gradually reduced participants' heart rate and led into the cool-down.

\subsection{Measures}

The overall measures collected in this study were health, physical, psychosocial, and demographic related factors before and following the 8-week intervention. Physical measures were taken for the health and physical measures, whereas the psychosocial and demographic measures were collected in a paper-based survey.

\subsubsection{Health Measures}

Anthropometrics: Weight was measured in pounds using a scale. Height was measured using a tape measure, which ran from the base of the floor along the wall. BMI $\left(\mathrm{kg} / \mathrm{m}^{2}\right)$ was calculated using height in centimeters and weight measured in kilograms. Waist circumference was measured in inches using a tape measure.

Blood pressure: Systolic blood pressure (SBP) and Diastolic blood pressure (DBP) were measured with an Omron ${ }^{\circledR}$ digital blood pressure monitor (model HEM907XL) and measured in milligrams of mercury (mmHg). Heart rate (HR) was measured with an Omron ${ }^{\circledR}$ digital blood pressure monitor (model HEM-907XL) in beats per minute (bpm).

\subsubsection{Physical Measures}

Flexibility: Flexibility was assessed using the sit-andreach test [39].

Aerobic endurance: Aerobic endurance was measured using the Rockport Walking Test, which is an estimate of maximal aerobic capacity (VO2max) [40]. The Rockport Walking Test was time recorded for the amount of time it took to walk one mile on a track. Following the one mile walk test, pulse for the Rockport Walking Test was measured using a pulse oximeter (Contec ${ }^{\mathrm{TM}}$ ) placed on the right index finger and the time was recorded. VO2max was estimated using the following equation for VO2max $(\mathrm{ml} / \mathrm{kg} / \mathrm{min})=132.853-0.1692 *($ body mass in $\mathrm{kg})-$ $0.3877 *$ (age in years) $+6.315^{*}(\mathrm{sex})-3.2649 *$ (time in minutes) $-0.1565 *(\mathrm{HR})$ where sex indicating as " 0 " for female. The Rockport Walking Test was originally introduced and validated by Kline and colleagues [40]. It has continued to be validated and supported in adults across multiple studies $(r=0.68-0.95)$ [41].

\subsubsection{Psychosocial Measures}

Exercise motivation: Exercise motivation was measured using the Exercise Motivation Inventory-2 (Markland \&
Ingledew, 1997, EMI-2). EMI-2 included 51-items, each rated on a Likert type scale ranging from 0 (not at all true for me) to 5 (very true for me). The scale included 14 subscales: stress management, revitalization, enjoyment, challenge, social recognition, affiliation, competition, health pressures, ill-health avoidance, positive health, weight management, appearance, strength and endurance, and nimbleness. The Cronbach's Alpha measuring internal consistency for the EMI-2 was reported to range from $0.69-0.95$ [42].

\subsubsection{Demographic Measures}

Participants were asked to fill out an online survey with demographic information including age, marital status, education level, employment status, occupation, number of children, and number of hours worked per week. Adherence to the program was measured by adding the number of classes that each participant attended based on the instructor's recorded attendance and then computing the mean percentage of attendance.

\subsection{Measurement Procedures}

Anywhere from one to five participants had their baseline taken concurrently. For the baseline assessment procedures, participants sat quietly for 5 minutes before blood pressure was measured. Blood pressure was taken in the left arm using an electronic blood pressure machine while the participant was seated in a chair with legs uncrossed. Waist circumference was taken by placing the tape measure at the start of the hipbone, bringing it all around in level with the belly button while the participant was standing. Weight was taken by participants taking their shoes off and stepping on the calibrated weight scale. Flexibility was taken by participants sitting on the floor with legs straight against the sit-and-reach box and soles placed flat against the box. Specifically, for this measure, participants reached forward with palms downward and pushed the marker as far as they could, and the score was recorded to the nearest half-inch. For the aerobic fitness test, participants were required to walk briskly on an outside track for one mile, and the time taken to complete the walk and pulse right after the walk were measured. Participants also filled out the EMI-2, their age and height for the baseline. At the completion of the 8-week intervention, participants were administered post-measures including weight, waist circumference, HR, SBP and DBP, flexibility, and aerobic endurance.

\subsection{Statistical Analysis}

All statistical analyses were computed using IBM SPSS version 24. A descriptive analysis was conducted on all demographic and outcomes variables. A Shapiro-Wilk test of normality was conducted to determine whether the variables were normally distributed. To identify the differences in pre- and post- intervention measures, a paired samples t-test was conducted for each of the outcome variables which included BMI, weight, flexibility, SBP, DBP, HR, waist circumference, aerobic fitness, and exercise motivation. 


\section{Results}

A total of 21 female participants completed the baseline assessment and were enrolled in the study. Two participants dropped out of the study following the baseline assessment and three participants were lost to follow-up by the post-intervention. A total of 16 participants completed the intervention and the postintervention assessment (76\% retention rate).

Descriptive analyses indicated that majority of the participants were married (80\%) and foreign-born (90\%), with an associate's or bachelor's degree (75\%) and had 1-2 children (55\%). Almost all participants were employed outside of the home (90\%), working 40 hours or more (65\%) per week, and were in a health-related occupation (55\%) (see Table 1). Adherence to the Zumba classes was $42.46 \%$ among participants who completed the post-intervention.

For outcome measures, paired samples t-test indicated a significant reduction in body weight $(-3.18 \pm 2.6$ lbs., $p<$ $0.001)$, BMI $\left(-0.44 \pm 0.49 \mathrm{~kg} / \mathrm{m}^{2}, p=0.002\right)$, and increase in flexibility $(1.93 \pm 3.22, p=0.035)$ among study participants from pre-to post measures. There were no statistically significant differences in participants' waist circumference, SBP, DBP, HR, and aerobic fitness (see Table 2).

In regards to exercise motivation subscales from the EMI-2, there were no statistically significant differences in revitalization $(-.354 \pm 1.238, p=0.270)$, stress management $(-0.359 \pm 1.13, p=0.228)$, enjoyment $(-0.406 \pm 1.103, \quad p=0.161)$, challenge $\quad(-0.438 \pm 1.116$, $p=0.138)$, social recognition $-0.688 \pm 1.898, p=0.171)$, competition $(-0.641 \pm 1.782, \mathrm{p}=0.171)$, health pressures $(-0.042 \pm 1.539, p=0.915)$, ill-health avoidance $(-0.125 \pm 1.258$, $p=0.697)$, positive health $(-0.271 \pm 1.070, p=0.327)$, weight management $(0.176 \pm 1.430, p=0.618)$, appearance (0.016 $\pm 1.337, \quad p=0.963)$, strength and endurance $(-0.328 \pm 1.036, p=0.224)$, and nimbleness $(-0.208 \pm 1.222$, $p=0.506)$. However, affiliation scores increased among participants overall with statistical significance $(-0.750 \pm 1.384$, $p=0.047$ ) (see Figure 1).

Table 1. Demographic characteristics among study sample $(n=21)$

\begin{tabular}{|c|c|}
\hline Variable & Mean (SD) \\
\hline Age & $54.70( \pm 10.829)$ \\
\hline Weight & $149.25( \pm 35.131)$ \\
\hline BMI & $26.77( \pm 5.034)$ \\
\hline Waist circumference (inches) & $37.11( \pm 5.368)$ \\
\hline Systolic blood pressure & $140.75( \pm 11.135)$ \\
\hline \multirow[t]{2}{*}{ Diastolic blood pressure } & $85.50( \pm 9.231)$ \\
\hline & $\mathrm{n}(\%)$ \\
\hline \multicolumn{2}{|l|}{ Marital Status } \\
\hline Single & $2(10.0)$ \\
\hline Married & $16(80.0)$ \\
\hline Divorced & $2(10.0)$ \\
\hline \multicolumn{2}{|l|}{ Education Level } \\
\hline High school graduate & $1(5.0)$ \\
\hline Associate's or Bachelor's Degree & $15(75.0)$ \\
\hline Master's or Doctorate Degree & $4(20.0)$ \\
\hline \multicolumn{2}{|l|}{ Children } \\
\hline Yes & $17(85.0)$ \\
\hline No & $3(15.0)$ \\
\hline \multicolumn{2}{|l|}{ Number of Children } \\
\hline 0 & $3(15.0)$ \\
\hline $1-2$ & $11(55.0)$ \\
\hline $3+$ & $6(30.0)$ \\
\hline \multicolumn{2}{|l|}{ Employed outside of home } \\
\hline Yes & $18(90.0)$ \\
\hline No & $2(10.0)$ \\
\hline \multicolumn{2}{|l|}{ Hours worked per week } \\
\hline Do not work & $2(10.0)$ \\
\hline Less than 40 & $5(25.0)$ \\
\hline 40 or above & $13(65.0)$ \\
\hline \multicolumn{2}{|l|}{ Health related occupation } \\
\hline Yes & $11(55.0)$ \\
\hline No & $8(20.0)$ \\
\hline \multicolumn{2}{|l|}{ Born in the Philippines } \\
\hline Yes & $18(90.0)$ \\
\hline No & $2(10.0)$ \\
\hline
\end{tabular}

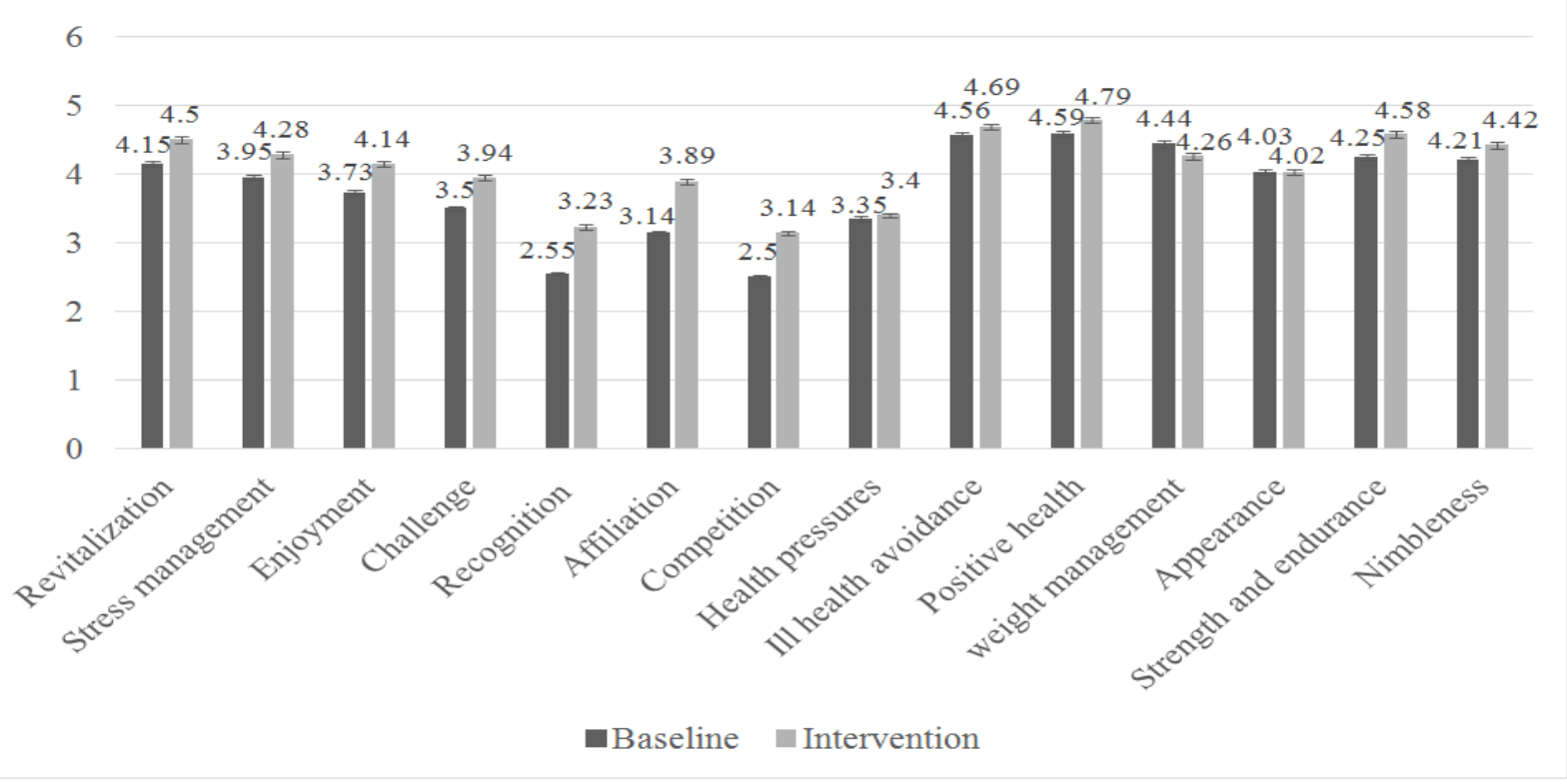

Figure 1. Changes in exercise motivation subscales pre and post test $(n=16)$ 
Table 2. Pre- and Post Intervention changes in physical and health measures $(n=16)$

\begin{tabular}{rcccc}
\hline \multicolumn{1}{c}{ Variable } & Baseline & Post-Intervention & Change & p-value (t-test) \\
\hline Weight (lbs.) & $142.94 \pm 15.62$ & $139.75 \pm 15.60$ & $3.18 \pm 2.61$ & $<0.001^{*}$ \\
BMI (kg/m²) & $25.97 \pm 2.41$ & $25.53 \pm 2.48$ & $0.44 \pm 0.49$ & $0.002^{*}$ \\
Waist Cir. (in.) & $36.76 \pm 4.60$ & $35.43 \pm 3.48$ & $1.33 \pm 2.58$ & 0.058 \\
Systolic BP (mmHg) & $140.81 \pm 10.97$ & $132.00 \pm 23.73$ & $8.81 \pm 22.54$ & 0.139 \\
Diastolic BP (mmHg) & $84.88 \pm 9.46$ & $84.88 \pm 13.58$ & $0.00 \pm 12.76$ & 1.000 \\
Resting HR (bpm) & $74.00 \pm 9.42$ & $77.81 \pm 14.57$ & $-3.81 \pm 12.10$ & 0.227 \\
Flexibility (cm) & $28.87 \pm 6.07$ & $30.8 \pm 5.90$ & $-1.93 \pm 3.22$ & $0.035^{*}$ \\
Aerobic Fitness & $21.80 \pm 17.68$ & $24.43 \pm 8.60$ & $-2.63 \pm 14.22$ & 0.470 \\
(ml/kg/min) & & & & \\
\hline
\end{tabular}

*significant at the $\mathrm{p}<0.05$ level

Values are expressed as the mean and standard deviation (SD)

\section{Discussion}

To our knowledge, this was the first study using a structured PA intervention, Zumba, that assessed physical and health outcomes among midlife Filipino women. This Zumba intervention served as a culturally relevant activity that was highly regarded by the Filipino community and as a prioritized approach for being physically active. This community-based intervention, which included an instructor from the same ethnic background, and was held at a Filipino CBO where many people of this ethnicity congregate, was an identified strength to this study as they provided a unique alternative to traditional PA interventions in the field. A recent systematic review assessing culturally specific PA interventions in older Asian American identified that the majority of studies have been conducted among Chinese Americans, and there is large heterogeneity among strategies used for intervention tailoring [32]. Thus, our study aimed to further the knowledge gap in providing how culturally specific interventions can improve PA related outcomes such as motivation, cardiovascular status and physiological related measures [32].

Of interest to this study, Zumba has emerged as a common type of structured PA in the US and globally. Zumba is an aerobic fitness program which combines Latin and other international upbeat music with dance moves and can enhance aerobic fitness [43]. A few intervention studies have examined the effectiveness of Zumba on health and physical fitness outcomes among multiple clinical and non-clinical populations [11,44,45,46,47]. A systematic review conducted on the overall health benefits of Zumba reported that it enhanced aerobic and cardiovascular outcomes such as weight loss (1-3.6\% reduction), body mass index (BMI) (1.1-3.7\%), and waist circumference (3.5-4\%) in participants within programs that lasted 8-40 weeks [47]. To that end, one can also argue that Zumba may help reduce more common barriers that Filipinos face to engaging in PA, since it includes a strong cultural component that can enhance activity among ethnic populations, especially when it is tailored to a specific culture [29]. Additionally, it is important to note that dance, which includes Zumba, was reported as the second most common leisure PA among women of older age [48]. Drawing upon this finding, dance related activities may hold potentials to increase PA and improve health and physical outcomes among Filipino women.

It is evident that the baseline measures including blood pressure and BMI were relatively high among our participants. Main findings from this study indicated that the Zumba intervention led to significant reduction in weight and BMI as well as an increase in flexibility. This finding is consistent with other studies, where a Zumba dance program showed similar positive effects in comparable populations [45,46,49,50]. Specifically, research indicated that following a 16-week intervention, diabetic patients in intervention group gained higher aerobic capacity, flexibility, and intrinsic motivation, in addition to reduction in weight, BMI, and waist circumference [50]. However, it is important to note that the intervention in this study was twice the length of ours, leading to more favorable effects following a longer intervention period. Additional evidence has also revealed that Zumba based interventions improve SBP, but this finding was not replicated in our study $[11,49]$.

Importantly, even though Zumba is a highly regarded program among Filipinos [37,51], it has been scarcely evaluated with respect to its potential impacts on physical and psychological health outcomes. With respect to its psychological outcomes, researchers have investigated the changes in exercise motivation after a Zumba program and found increases in intrinsic motivation [50]. This finding is interesting in that the present findings could suggest an increase in exercise motivation (related to its intrinsic aspects such exercise-enjoyment, sense of challenge, etc.) but was only significant with respect to participants feeling higher levels of affiliation due to the Zumba program. Exercise motivation can serve as an important determinant of PA levels, and the incorporation of Zumba can provide more intrinsic means of participation such as enjoyment rather than conforming to a rigid exercise regimen, which can deter middle-aged women from participating. Future studies can incorporate more rigorous methods for evaluating exercise motivation in the context of more autonomous activities such as Zumba [52].

The present study included several limitations. First, as this is a feasibility study, its sample size was small. Second, the study lacked a control group to compare changes in outcome effect. Therefore, future studies would benefit from increasing sample size and including control and/or waitlist control groups. It is also important to note that this program was on the lower spectrum of an intervention period, only being 8-weeks long [47]. Additionally, although there was a normal retention rate, the adherence levels to the present program were lower than other studies. Thus, intervention of at least 8 weeks or ideally longer durations, with more optimal retention rates, could have greater contributions to extant body of knowledge. Last, but not least, the lack of control over potentially confounding variables such as participants engaging in other types of PA outside of the intervention, 
and a lack of information on dietary behaviors, could have impacted our results, hence the need for long-term monitoring and controlling these variables in future research.

In conclusion, midlife women are at risk towards a plethora of health issues, including weight gain, increased blood pressure, decreased aerobic capacity, and decreased bone mineral density among other conditions [53]. It is important that a variety of PA interventions are designed and tested among women of midlife ages who may face disparities in meeting PA guidelines. Of specific interest to this study, Filipino women remain a highly understudied group who can benefit from alternative PA interventions due to high prevalence of chronic disease within the community [16]. Despite its limitation, findings from the present study suggest that a community-based Zumba intervention can potentially have beneficial effects on midlife Filipino women hence can be a feasible and acceptable approach to enhancing their health-related outcomes. Future research can examine long-term impact of Zumba and other exercise modalities for chronic disease prevention and management among understudied midlife Filipino and Asian women at risk.

\section{Acknowledgements}

The authors wish to thank the community members and leaders of the Philippine Community of Southern New Jersey who provided their support and time to helping with this study, and Temple University Department of Kinesiology for the funding to conduct this study.

\section{Compliance with Ethical Standards}

The authors declare that they have no conflicts of interest. All procedures performed in studies involving human participants were in accordance with the ethical standards of the institutional and/or national research committee and with the 1964 Helsinki declaration and its later amendments or comparable ethical standards.

\section{References}

[1] CDC. (2015). Physical Activity Basics. Physical Activity Basics. Retrieved November 12, 2016, from https://www.cdc.gov/physicalactivity/basics/index.htm

[2] Albright, C. L., Steffen, A. D., Novotny, R., Nigg, C. R., Wilkens, L. R., Saiki, K., ... Brown, W. J. (2012). Baseline Results from Hawaii’s Nā Mikiniiki Project: A Physical Activity Intervention Tailored to Multiethnic Postpartum Women. Women \& Health, 52(3), 265-291.

[3] Li, J., \& Siegrist, J. (2012). Physical activity and risk of cardiovascular disease--a meta-analysis of prospective cohort studies. International Journal of Environmental Research and Public Health, 9(2), 391-407.

[4] Durstine, J. L., Gordon, B., Wang, Z., \& Luo, X. (2013). Chronic disease and the link to physical activity. Journal of Sport and Health Science, 2(1), 3-11.

[5] Centers for Disease Control and Prevention. (2017, September 27). National Center for Chronic Disease Prevention and Health Promotion, Division of Nutrition, Physical Activity, and Obesity. Data, Trend and Maps. Retrieved from https://www.cdc.gov/nccdphp/dnpao/data-trends-maps/index.html.
[6] Booth, F. W., Roberts, C. K., \& Laye, M. J. (2012). Lack of exercise is a major cause of chronic diseases. Comprehensive Physiology, 2(2), 1143-1211.

[7] Carlin, A., Perchoux, C., Puggina, A., Aleksovska, K., Buck, C., Burns, C., ... Boccia, S. (2017). A life course examination of the physical environmental determinants of physical activity behavior: A "Determinants of Diet and Physical Activity" (DEDIPAC) umbrella systematic literature review. PloS One, 12(8), e0182083.

[8] Angosta, A. D., \& Serafica, R. (2017). Assessing Physical Activity Levels in Filipino Americans With Hypertension Using the Rapid Assessment of Physical Activity Questionnaire. Home Health Care Management \& Practice, 29(2), 91-95.

[9] Belza, B., Walwick, J., Shiu-Thornton, S., Schwartz, S., Taylor, M., \& LoGerfo, J. (2004). Older adult perspectives on physical activity and exercise: voices from multiple cultures. Preventing Chronic Disease, 1(4), A09.

[10] Afable-Munsuz, A., Ponce, N. A., Rodriguez, M., \& Perez-Stable, E. J. (2010). Immigrant generation and physical activity among Mexican, Chinese \& Filipino adults in the U.S. Social Science \& Medicine, 70(12), 1997-2005.

[11] Araneta, M. R., \& Tanori, D. (2015). Benefits of Zumba Fitness ${ }^{\circledR}$ among sedentary adults with components of the metabolic syndrome: a pilot study. The Journal of Sports Medicine and Physical Fitness, 55(10), 1227-1233.

[12] Kao, D., Carvalho Gulati, A., \& Lee, R. E. (2016). Physical Activity Among Asian American Adults in Houston, Texas: Data from the Health of Houston Survey 2010. Journal of Immigrant and Minority Health, 18(6), 1470-1481.

[13] Kao, D., Gulati, A. C., \& Lee, R. E. (2016). Physical Activity Among Asian American Adults in Houston, Texas: Data from the Health of Houston Survey 2010. Journal of Immigrant and Minority Health, 18(6), 1470-1481.

[14] Palaniappan, L. P., Araneta, M. R. G., Assimes, T. L., BarrettConnor, E. L., Carnethon, M. R., Criqui, M. H., ... Wong, N. D. (2010). Call to Action: Cardiovascular Disease in Asian Americans A Science Advisory From the American Heart Association. Circulation, 122(12), 1242-1252.

[15] Becerra, M. B., Herring, P., Marshak, H. H., \& Banta, J. E. (2015). Social Determinants of Physical Activity Among Adult AsianAmericans: Results from a Population-Based Survey in California. Journal of Immigrant and Minority Health, 17(4), 1061-1069.

[16] Yi, S. S., Roberts, C., Lightstone, A. S., Shih, M., \& Trinh-Shevrin, C. (2015). Disparities in meeting physical activity guidelines for Asian Americans in two metropolitan areas in the United States. Annals of epidemiology, 25(9), 656-660.e2.

[17] Largest U.S. Immigrant Groups over Time, 1960-Present. (2013, October 2). migrationpolicy.org. Retrieved May 4, 2017, from http://www.migrationpolicy.org/programs/data-hub/charts/largestimmigrant-groups-over-time.

[18] Bhimla, A., Yap, L., Lee, M., Seals, B., Aczon, H., \& Ma, G. X. (2017). Addressing the Health Needs of High-Risk Filipino Americans in the Greater Philadelphia Region. Journal of Community Health, 42(2), 269-277.

[19] Ceria-Ulep, C. D., Serafica, R. C., \& Tse, A. (2011). Filipino Older Adults' Beliefs About Exercise Activity. Nursing Forum, 46(4), 240-250.

[20] Kandula, N. R., \& Lauderdale, D. S. (2005). Leisure Time, Non-leisure Time, and Occupational Physical Activity in Asian Americans. Annals of Epidemiology, 15(4), 257-265.

[21] Staimez, L. R., Weber, M. B., Narayan, K. M. V., \& Oza-Frank, R. (2013). A systematic review of overweight, obesity, and type 2 diabetes among Asian American subgroups. Current Diabetes Reviews, 9(4), 312-331.

[22] Vargas, P., \& Jurado, L.-F. (2015). Dietary Acculturation among Filipino Americans. International Journal of Environmental Research and Public Health, 13(1), 16.

[23] Ursua, R. A., Islam, N. S., Aguilar, D. E., Wyatt, L. C., Tandon, S. D., Abesamis-Mendoza, N., ... Trinh-Shevrin, C. (2013). Predictors of Hypertension Among Filipino Immigrants in the Northeast US. Journal of Community Health, 38(5), 847-855.

[24] Bayog, M. L., \& Waters, C. M. (2017). Cardiometabolic risks, lifestyle health behaviors and heart disease in Filipino Americans. European Journal of Cardiovascular Nursing, 16(6), 522-529. 
[25] Langenberg, C., Araneta, M. R. G., Bergstrom, J., Marmot, M., \& Barrett-Connor, E. (2007). Diabetes and Coronary Heart Disease in Filipino-American Women: Role of Growth and Life-Course Socioeconomic Factors. Diabetes care, 30(3), 535-541.

[26] Ryan, C., Shaw, R., Pliam, M., Zapolanski, A. J., Murphy, M., Valle, H. V., \& Myler, R. (2000). Coronary heart disease in Filipino and Filipino-American patients: prevalence of risk factors and outcomes of treatment. The Journal of Invasive Cardiology, 12(3), 134-139.

[27] Choi, S. E., Liu, M., Palaniappan, L. P., Wang, E. J., \& Wong, N. D. (2013). Gender and ethnic differences in the prevalence of type 2 diabetes among Asian subgroups in California. Journal of Diabetes and Its Complications, 27(5), 429-435.

[28] Maxwell, A. E., Bastani, R., Vida, P., \& Warda, U. S. (2002). Physical activity among older Filipino-American women. Women and Health, 36(1), 67-79.

[29] Kaholokula, J. K., Look, M., Mabellos, T., Zhang, G., de Silva, M., Yoshimura, S., ... Sinclair, K. A. (2017). Cultural Dance Program Improves Hypertension Management for Native Hawaiians and Pacific Islanders: a Pilot Randomized Trial. Journal of Racial and Ethnic Health Disparities, 4(1), 35-46.

[30] Kim, M. T., Han, H.-R., Song, H.-J., Lee, J.-E., Kim, J., Ryu, J. P., \& Kim, K. B. (2009). A community-based, culturally tailored behavioral intervention for Korean Americans with type 2 diabetes. The Diabetes Educator, 35(6), 986-994.

[31] Nam, S., Janson, S. L., Stotts, N. A., Chesla, C., \& Kroon, L. (2012). Effect of Culturally Tailored Diabetes Education in Ethnic Minorities With Type 2 Diabetes: A Meta-analysis. The Journal of Cardiovascular Nursing, 27(6), 505-518.

[32] Katigbak, C., Flaherty, E., Chao, Y.-Y., Nguyen, T., Cheung, D., \& Yiu-Cho Kwan, R. (2018). A Systematic Review of Culturally Specific Interventions to Increase Physical Activity for Older Asian Americans. The Journal of Cardiovascular Nursing.

[33] Tomioka, M., Braun, K. L., Cook, V. A., Compton, M., \& Wertin, K. (2014). Improving behavioral and clinical indicators in Asians and Pacific Islanders with diabetes: Findings from a community clinic-based program. Diabetes research and clinical practice, 104(2), 220-225.

[34] Barbara A. Israel, Amy J. Schulz, Edith A. Parker, \& Becker, and A. B. (1998). REVIEW OF COMMUNITY-BASED RESEARCH: Assessing Partnership Approaches to Improve Public Health. Annual Review of Public Health, 19(1), 173-202.

[35] Israel, B. A., Schulz, A. J., Parker, E. A., \& Becker, A. B. (2008). Community-Based Participatory Research for Health. Presented at the Jossey-Bass. Retrieved from https://www.scholars.northwestern.edu/en/publications/criticalissues-in-developing-and-following-community-based-parti-3.

[36] McAllister, C. L., Green, B. L., Terry, M. A., Herman, V., \& Mulvey, L. (2003). Parents, practitioners, and researchers: community-based participatory research with early head start. American Journal of Public Health, 93(10), 1672-1679.

[37] Stannard, S., Vaughan, C., Swift, O., Robinson, G., Altaf, S. A., \& McGarry, A. (2015). Women seafarers' health and welfare survey. International Maritime Health, 66(3), 123-138.

[38] dela Cruz, F. A., Padilla, G. V., \& Butts, E. (1998). Validating a short acculturation scale for Filipino-Americans. Journal of the American Academy of Nurse Practitioners, 10(10), 453-460.
[39] Wells, K. F., \& Dillon, E. K. (1952). The Sit and Reach-A Test of Back and Leg Flexibility. Research Quarterly. American Association for Health, Physical Education and Recreation, 23(1), 115-118.

[40] Kline, G. M., Porcari, J. P., Hintermeister, R., Freedson, P. S., Ward, A., McCarron, R. F., ... Rippe, J. M. (1987). Estimation of VO2max from a one-mile track walk, gender, age, and body weight. Medicine and Science in Sports and Exercise, 19(3), 253-259.

[41] Fenstermaker, K. L., Plowman, S. A., \& Looney, M. A. (1992) Validation of the Rockport Fitness Walking Test in females 65 years and older. Research Quarterly for Exercise and Sport, 63(3), 322-327.

[42] Markland, D., \& Ingledew, D. K. (1997). The measurement of exercise motives: Factorial validity and invariance across gender of a revised Exercise Motivations Inventory. British Journal of Health Psychology, 2(4), 361-376.

[43] Mayo Clinic. (2017). What is Zumba? Mayo Clinic. Retrieved May 8, 2017, from http://mayoclinic.org.

[44] Delextrat, A., Bateman, J., Esser, P., Targen, N., \& Dawes, H. (2016). The potential benefits of Zumba Gold( $\left({ }^{\circledR}\right)$ in people with mild-to-moderate Parkinson's: Feasibility and effects of dance styles and number of sessions. Complementary Therapies in Medicine, 27, 68-73.

[45] Domene, P. A., Moir, H. J., Pummell, E., Knox, A., \& Easton, C. (2016). The health-enhancing efficacy of Zumba ${ }^{\circledR}$ fitness: An 8week randomised controlled study. Journal of Sports Sciences, 34(15), 1396-1404.

[46] Rossmeissl, A., Lenk, S., Hanssen, H., Donath, L., SchmidtTrucksäss, A., \& Schäfer, J. (2016). ZumBeat: Evaluation of a Zumba Dance Intervention in Postmenopausal Overweight Women. Sports, 4(1), 5.

[47] Vendramin, B., Bergamin, M., Gobbo, S., Cugusi, L., Duregon, F., Bullo, V., ... Ermolao, A. (2016). Health Benefits of Zumba Fitness Training: A Systematic Review. PM\&R, 8(12), 1181-1200.

[48] Fan, J. X., Kowaleski-Jones, L., \& Wen, M. (2013). Walking or dancing: patterns of physical activity by cross-sectional age among U.S. women. Journal of Aging and Health, 25(7), 1182-1203.

[49] Cugusi, L., Wilson, B., Serpe, R., Medda, A., Deidda, M., Gabba, S., ... Working Group of Gender Cardiovascular Disease of the Italian Society of Cardiology. (2016). Cardiovascular effects, body composition, quality of life and pain after a Zumba fitness program in Italian overweight women. The Journal of Sports Medicine and Physical Fitness, 56(3), 328-335.

[50] Krishnan, S., Tokar, T. N., Boylan, M. M., Griffin, K., Feng, D., Mcmurry, L., ... Cooper, J. A. (2015). Zumba ${ }^{\circledR}$ dance improves health in overweight/obese or type 2 diabetic women. American Journal of Health Behavior, 39(1), 109-120.

[51] Giffard-Foret, P. (2013). Asian women at work: Interview with Lina Cabaero, Coordinator of Asian women at work. Australian Options, (72), 25.

[52] Nieri, T., \& Hughes, E. (2016). All about Having Fun: Women’s Experience of Zumba Fitness. Sociology of Sport Journal, 33(2), 135-145.

[53] Kendall, K. L., \& Fairman, C. M. (2014). Women and exercise in aging. Journal of Sport and Health Science, 3(3), 170-178. 